\title{
A Comprehensive Performance Assessment of the Modified Philip-Dunne Infiltrometer
}

\author{
Zuhier Alakayleh ${ }^{1}$, Xing Fang ${ }^{1, *}$ (D) and T. Prabhakar Clement ${ }^{2}$ \\ 1 Department of Civil Engineering, Auburn University, Auburn, AL 36849-5337, USA; zta0003@auburn.edu \\ 2 Department of Civil, Construction and Environmental Engineering, The University of Alabama, Tuscaloosa, \\ AL 35487, USA; pclement@ua.edu \\ * Correspondence: xing.fang@auburn.edu; Tel.: +1-334-844-8778; Fax: +1-334-844-6290
}

Received: 17 August 2019; Accepted: 6 September 2019; Published: 10 September 2019

\begin{abstract}
This study aims at furthering our understanding of the Modified Philip-Dunne Infiltrometer (MPDI), which is used to determine the saturated hydraulic conductivity $K_{s}$ and the Green-Ampt suction head $\Psi$ at the wetting front. We have developed a forward-modeling algorithm that can be used to simulate water level changes inside the infiltrometer with time when the soil hydraulic properties $K_{s}$ and $\Psi$ are known. The forward model was used to generate 30,000 water level datasets using randomly generated values of $K_{S}$ and $\Psi$ values. These model data were then compared against field-measured water level drawdown data collected for three types of soil. The Nash-Sutcliffe efficiency (NSE) was used to assess the quality of the fit. Results show that multiple sets of the model parameters $K_{s}$ and $\Psi$ can yield drawdown curves that can fit the field-measured data equally well. Interestingly, all the successful sets of parameters (delineated by NSE $\geq$ the threshold value) give $K_{s}$ values converged to a valid range that is fully consistent with the tested soil texture class. However, $\Psi$ values varied significantly and did not converge to a valid range. Based on these results, we conclude that the MPDI is a useful field method to estimate $K_{s}$ values, but it is not a robust method to estimate $\Psi$ values. Further studies are needed to improve the experimental procedures that can yield more sensitive data that can help uniquely identify $K_{s}$ and $\Psi$ values.
\end{abstract}

Keywords: infiltration; hydraulic conductivity; suction head; measurement technique; forward model; Green-Ampt model

\section{Introduction}

Saturated hydraulic conductivity $K_{s}$ is one of the most important parameters that control the water seepage processes through the soil profile [1-5]. The value of $K_{s}$ depends on the size and type of mineral present in the soil; for example, the presence of fine minerals such as silt and clay can greatly reduce $K_{s}$ values [6-9]. In addition, the value of $K_{s}$ decreases with a reduction in the effective porosity of the system [9-11].

Analyzing the undisturbed soil core taken from the field is a common method to determine $K_{s}$ in the laboratory using either the constant- or falling-head permeameter [12]. The soil core method has some challenges including macropores created by insertion of the ring, and relatively small sample size that may not yield a representative $K_{s}$ value $[5,13]$. To overcome these disadvantages, several field techniques have been developed to measure the in situ saturated hydraulic conductivity of the soil. However, natural variability of the soil properties and limitations of the field techniques such as sample size and flow geometry could also result in inaccurate estimation of the field-scale hydraulic properties $[5,14,15]$.

One of the common devices used in the field is the Guelph permeameter that was developed by Reynolds and Elrick [16]. This technique can measure the in situ saturated hydraulic conductivity 
using the constant head permeameter principle. This method employs a borehole (typically $31 \mathrm{~cm}$ depth and $3 \mathrm{~cm}$ radius) and uses the Mariotte principles to obtain a constant flow rate regardless of the decreasing water level within the permeameter.

Another simplified falling-head method that requires a small volume of water and short duration was developed by Bagarello et al. [17]. This permeameter is a ring, typically 20 to $30 \mathrm{~cm}$ diameter, inserted a short distance into the soil and then filled with a known volume of water. The time needed for the total volume of water to infiltrate is measured along with the initial and final water contents of the soil to estimate the value of $K_{s}$.

Philip [18] introduced an approximate analysis based on the Green-Ampt theory to estimate $K_{s}$ and the Green-Ampt suction head $\Psi$ at the wetting front from the drawdown data of a falling-head permeameter. This method, known as the Phillip-Dunne permeameter, uses a cylindrical tube that is vertically inserted into a borehole at a given depth, typically $15 \mathrm{~cm}$, within an unsaturated soil profile. Water is rapidly introduced into the system and the initial height $H_{\text {in }}$ is recorded at time $t=0$. The data analysis procedure employs the Green-Ampt model after transforming the actual three-dimensional flow system into an equivalent spherically symmetrical flow configuration.

Ahmed et al. [2] introduced a modified version of the Philip-Dunne permeameter [18], known as the Modified Philip-Dunne Infiltrometer (MPDI). The MPDI involves applying the device near the surface rather than in a borehole that results in changing the flow configuration of the infiltrated water. The device is inexpensive, easy to use, and requires a minimal amount of water. These advantages make it as a cost-effective method to rapidly determine $K_{s}$ at the surface to evaluate the infiltration capacity of the soil. The procedure for data collection and analysis is also described in ASTM-D8152-18 [19]. This method will be further reviewed in detail in the background and governing equations section, since the focus of this study is to further understand the MPDI theory.

Several studies are available in the literature that are aimed at evaluating the performance of different field techniques used for measuring the field-scale soil hydraulic properties. The saturated hydraulic conductivity was measured at five different locations and at four soil depths by Mohanty et al. [3] to evaluate the relative performance of the Guelph permeameter, the velocity permeameter [20], the disk permeameter [21], and the double-tube method [22]. Undisturbed soil cores were also collected from all the locations to determine the saturated hydraulic conductivity in the laboratory. The measured $K_{s}$ values were the lowest when Guelph permeameter was used, while the larger values were measured by the disk permeameter and the double-tube method. The velocity permeameter gave hydraulic conductivity values closer to the values estimated in the laboratory. Reynolds et al. [5] compared the $K_{s}$ values estimated using the tension infiltrometer [21] and the pressure infiltrometer (a single-ring, steady-flow technique) [23] with laboratory measurements and found that the $K_{s}$ values were significantly different even though the sample size was the same. Gómez et al. [24] determined $K_{s}$ and $\Psi$ values using different field techniques. The primary goal of their study was to compare the performance of the falling head, the single ring, the rainfall [25], and the tension infiltrometer for the assessment of infiltration rate at a field site. The differences in measured $K_{s}$ values using different techniques were smaller than the differences observed for the $\Psi$ values. The $\Psi$ values varied considerably and relatively large $\Psi$ values obtained using the analysis of Philip [18] for the falling-head infiltrometer. The authors did not provide an explanation for obtaining the large $\Psi$ values. However, since the $\Psi$ values were higher than the average values for soils with the same textural class reported by others, the authors recommended using another method to estimate $\Psi$ rather than the Philip [18] method. Muñoz-Carpena et al. [26] compared the performance of the Philip-Dunne permeameter with the constant head permeameter and the Guelph permeameter. The measured $K_{s}$ values by the Philip-Dunne permeameter were greater than those values obtained using the Guelph permeameter by an order of magnitude. The laboratory constant head permeameter method gave $K_{s}$ values that ranged between the values estimated using the Philip-Dunne and Guelph permeameters. The authors explained that the variations were due to differences in water infiltration geometries and sample wetted volumes of the methods. Controlled laboratory measurements of $K_{s}$ for three 
types of media with different grain size distribution were completed by Nestingen et al. [27] in order to compare the accuracy and precision of the Modified Philip-Dunne Infiltrometer, the double-ring infiltrometer, and the minidisk infiltrometer [28]. To determine the accuracy of each device, the mean hydraulic conductivity value was compared with the value obtained by using the falling-head test. Results showed that the MPDI gave the correct trend of decreasing $K_{s}$ values by increasing the fine content of the media. The estimated $K_{s}$ values from the three methods were close to the values of the falling-head test. The most precise method was the double-ring method, followed by the MPDI, and the minidisk infiltrometers.

Our review indicates that several recent studies, including Weiss and Gulliver [29], García-Serrana et al. [30], Kristvik et al. [31], and Taguchi et al. [32], have used the MPDI approach to measure the in situ soil hydraulic parameters. None of these studies have evaluated the sensitivity of the MPDI theory to the variations of the soil hydraulic parameters. The objective of this study is to complete a comprehensive investigation of the sensitivity of the MPDI theory used for determining $K_{s}$ and $\Psi$ from the drawdown data collected using the MPDI.

\section{Methods}

\subsection{Background and Governing Equations}

Figure 1 shows the conceptual diagram of the MPDI. This modified version of the Philip-Dunne permeameter was originally developed by Ahmed et al. [2]. The apparatus is a transparent plastic open-ended tube of internal radius $r_{1}$ (typically $5 \mathrm{~cm}$ ) attached to a metal ring beveled from the edge for vertically inserting the system into an unsaturated soil for a distance of $L_{\max }$ (typically at about $5 \mathrm{~cm}$ ). Water is rapidly poured to the system and the initial height is $H_{\text {in }}$ at time $t=0$, and the water is allowed to infiltrate into the soil. During infiltration, the changes in water height in the tube $H\left(t_{j}\right)$ is recorded with time $\left(t_{j}, j=1,2, \ldots, n\right)$. The soil volumetric moisture content $\theta_{i n}$ at the beginning of the test, and $\theta_{s}$ at the end of the test are also recorded.

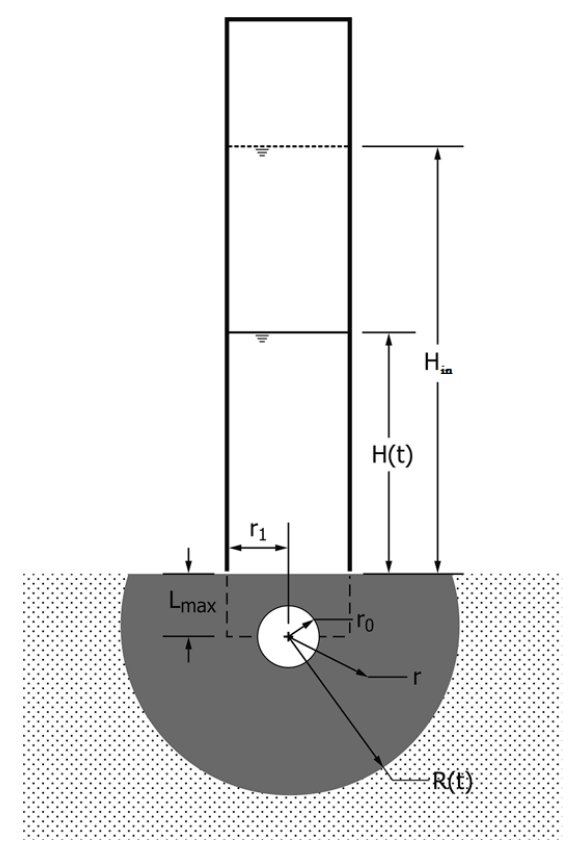

Figure 1. Notations used in the governing equations of the Modified Philip-Dunne Infiltrometer [33].

To analyze the drawdown data, Ahmed et al. [2] modified the procedure introduced by Philip [18] to account for the difference in the flow configuration due to the installation of the device closer to the surface, rather than inside a borehole. The wetted soil is represented as a capped sphere with a radius of $R\left(t_{j}\right)$ instead of the actual three-dimensional flow configuration. Another simplification that was 
applied by Philip [18] and followed by Ahmed et al. [2] is replacing the actual disk infiltration surface (of radius $r_{1}$ ) by a sphere with radius $r_{0}=0.5 \times r_{1}$. The surface area of the actual disk infiltration surface (of radius $r_{1}$ ) and the assumed sphere (of radius $r_{0}=0.5 \times r_{1}$ ) is the same.

Figure 1 shows the notations used to develop the governing equations for the MPDI. The geometry of the wetting front which is a capped sphere of radius $R\left(t_{j}\right)$ is used to express the cumulative infiltration at a given time using the initial and final volumetric moisture content of the soil enclosed within the sphere. A mass balance statement (Equation (1)) that equates the volume of water left in the infiltrometer at a given time $\left[H_{i n}-H\left(t_{j}\right)\right] \pi r_{1}^{2}$ with the cumulative infiltration occurred during the same time is used to compute $R\left(t_{j}\right)$ as a function of $H\left(t_{j}\right)$. This equation is only valid where the geometric shape of the wetting front remains constant at the sphere, typically at $R\left(t_{j}\right)$ with values greater than $\sqrt{r_{1}^{2}+L_{\max }^{2}}$.

$$
\left[H_{\text {in }}-H\left(t_{j}\right)\right] \pi r_{1}^{2}=\frac{\pi}{3}\left(\theta_{s}-\theta_{\text {in }}\right)\left[2 R^{3}\left(t_{j}\right)+3 R^{2}\left(t_{j}\right) L_{\max }-L_{\text {max }}^{3}-4 r^{3}\right]
$$

The flow velocity at the spherical infiltration surface $v_{c o}$ is given by differentiating Equation (1) with respect to time. Following Philip's approximation, the velocity is only driven by pressure and capillarity forces since they dominate over gravity during the short duration of the test. The pressure-capillary flow velocity across the spherical surface $v_{\mathcal{C}}(r)$ of radius $r\left(r_{0} \leq r<R\right)$ is given as [2]:

$$
v_{c}(r)=v_{c o}\left[\frac{2 r^{2}}{r^{2}+r L_{\max }}\right]=\left[\left(\theta_{s}-\theta_{i n}\right)\left(R^{2}\left(t_{j}\right)+R\left(t_{j}\right) L_{\max }\right) \frac{d R\left(t_{j}\right)}{d t}-2 r^{2} K_{s}\right]\left[\frac{1}{r^{2}+r L_{\max }}\right]
$$

The pressure-capillarity potential drop $\Delta P$ from the spherical source $r=r_{0}$ to the wetting front $r=$ $R\left(t_{j}\right)$ is given by applying Darcy's law: $\Delta P=\beta \int_{r_{0}}^{R\left(t_{j}\right)}\left[v_{\mathcal{c}}(r) / K_{s}\right] d r$. Substituting Equation (2) into Darcy's law yields the following equation (note, the exploratory factor $\beta$, equal to $\pi^{2} / 8$, is used to account for the change of flow path efficiency resulting from the replacement of the actual flow configuration) [2]:

$$
\Delta P=\frac{\pi^{2}}{8}\left[\left(\theta_{s}-\theta_{i n}\right) \frac{R^{2}\left(t_{j}\right)+R\left(t_{j}\right) L_{\max }}{K_{s}} \frac{d R\left(t_{j}\right)}{d t}-2 r_{0}{ }^{2}\right] \times \frac{\ln \frac{R\left(t_{j}\right)\left(r_{0}+L_{\max }\right)}{r_{0}\left(R\left(t_{j}\right)+L_{\max }\right)}}{L_{\max }}
$$

The pressure-capillarity potential drop from the spherical source to the wetting front is also given by $\Delta P=\Psi-P\left(t_{j}\right)$, where $P\left(t_{j}\right)$ is the pressure at the sphere source. $P\left(t_{j}\right)$ is determined by applying Darcy's law for the flux in the cylinder of soil encased within the infiltrometer $q=-K_{S}[d p / d z+1]$. This flux is the same as the rate of drop in the water height inside the infiltrometer $q=-\Delta H\left(t_{j}\right) / \Delta t_{j}$. Equating these two fluxes and integrating with $z$ will result in $P\left(t_{j}\right)=H\left(t_{j}\right)+L_{\max }-\left[\Delta H\left(t_{j}\right) / \Delta t_{j}\right]\left(L_{\max } / K_{S}\right)$. This leads to another expression for the pressure-capillarity potential drop between the spherical source to the wetting front [2].

$$
\Delta P=\Psi-P\left(t_{j}\right)=\Psi-H\left(t_{j}\right)-L_{\max }+\frac{\Delta H\left(t_{j}\right)}{\Delta t_{j}} \frac{L_{\max }}{K_{s}}
$$

By equating the previous two expressions of the pressure-capillarity potential drop from the spherical source to the wetting front (Equations (3) and (4)), Ahmed et al. [2] obtained the following equation that quantifies the temporal drop in the water height inside the infiltrometer as a function of the soil hydraulic properties $K_{s}$ and $\Psi$ :

$$
\Delta H_{S}\left(t_{j}\right)=\frac{K_{s}}{L_{\max }} \Delta t_{j}\left\{\begin{array}{l}
\frac{\pi^{2}}{8}\left(\theta_{s}-\theta_{i n}\right) \frac{R^{2}\left(t_{j}\right)+R\left(t_{j}\right) L_{\max }}{K_{S}} \frac{\Delta R\left(t_{j}\right)}{\Delta t_{j}} \frac{\ln \frac{R\left(t_{j}\right)\left(r+L_{\max }\right)}{r\left(R\left(t_{j}\right)+L_{\max }\right)}}{L_{\max }} \\
-\frac{\pi^{2}}{4} r^{2} \frac{\ln \frac{R\left(t_{j}\right)\left(r+L_{\max }\right)}{r\left(R\left(t_{j}\right)+L_{\max }\right)}}{L_{\max }}-\Psi+H\left(t_{j}\right)+L_{\max }
\end{array}\right\}
$$


Where $d R\left(t_{j}\right) / d t$ in Equations (2) and (3) are calculated as $\Delta R\left(t_{j}\right) / \Delta t_{j}$ in Equations (5) and (6), and $\Delta R\left(t_{j}\right)=R\left(t_{j}\right)-R\left(t_{j-1}\right)$. For each application of the MPDI, one measures the water height $H\left(t_{j}\right)$ at different time $t_{j}$ or records $t_{j}$ at different specified $H\left(t_{j}\right)$ until most of the water infiltrates into the soil. $R\left(t_{j}\right)$ is solved first using Equation (1) based on measured $H\left(t_{j}\right)$ values, and then $d R\left(t_{j}\right) / d t$ can be estimated. Equation (5) was used by Ahmed et al. [2] to fit $K_{s}$ and $\Psi$ values by minimizing the absolute difference between the time series of calculated head drop $\Delta H_{s}\left(t_{j}\right)$ and measured $\Delta H\left(t_{j}\right)$ data using the solver function available in Excel. Another method for setting the optimization procedure is to solve for $K_{s}$ and $\Psi$ using the following equation, which is a rearrangement of Equation (5), written to evaluate $\Delta t_{s j}$ and it can be used to fit with measured time intervals $\Delta t_{j}$ data.

$$
\Delta t_{s j}=\frac{\frac{\pi^{2}}{8}\left(\theta_{s}-\theta_{i n}\right) \frac{R^{2}\left(t_{j}\right)+R\left(t_{j}\right) L_{\max }}{K_{s}} \frac{\ln \frac{R\left(t_{j}\right)\left(r_{0}+L_{\max }\right)}{r_{0}\left(R\left(t_{j}\right)+L_{\max }\right)}}{L_{\max }} \Delta R\left(t_{j}\right)-\frac{L_{\max }}{K_{s}} \Delta H\left(t_{j}\right)}{\Psi-H\left(t_{j}\right)-L_{\max }+\frac{\pi^{2}}{4} r_{0}{ }^{2} \frac{\ln \frac{R\left(t_{j}\right)\left(r_{0}+L_{\max }\right)}{r_{0}\left(R\left(t_{j}\right)+L_{\max }\right)}}{L_{\max }}}
$$

Based on time-series data of $t_{j}$ and $H\left(t_{j}\right)(j=1,2, \ldots, n), \Delta t_{j}=t_{j}-t_{j-1}$ and $\Delta H\left(t_{j}\right)=H\left(t_{j}\right)-H\left(t_{j-1}\right)$ are estimated as observed/measured time intervals and head drops, respectively. $\Delta H_{s}\left(t_{j}\right)$ and $\Delta t_{s j}$ are the changes in the head drop and time intervals, computed using Equations (5) and (6), respectively. Therefore, one has a choice of fitting either (5) or (6) to fit the $K_{s}$ and $\Psi$ values, and in this study, we will fit both equations to understand their relative sensitivities. Also, since both (5) and (6) are nonlinear, the system can yield multiple combinations of $K_{s}$ and $\Psi$ that could fit the observations equally well. The question then is which of these solutions are feasible solutions? And can we accept or reject these values? What is the range of the accepted values of $K_{s}$ and $\Psi$ ? The goal of this study is to answer these questions to better understand the advantages and disadvantages of using the MPDI.

\subsection{Forward-Modeling Algorithm and Its Applications}

A forward-modeling code was developed and written in Visual Basic for Applications (VBA) available within Excel. The details of the algorithm which was used are summarized in Figure 2. Table 1 shows various applications of the forward-modeling code that are discussed in this study.

Table 1. The three different applications of the forward model.

\begin{tabular}{cccc}
\hline $\begin{array}{c}\text { Forward-Modeling } \\
\text { Application }\end{array}$ & Measured/Input & Simulated & Calculated/Output \\
\hline Application 1 & $\begin{array}{c}\text { Assumed } H_{i n} \text { and } \Delta H\left(t_{j}\right), \\
\text { known } K_{s} \text { and } \Psi\end{array}$ & $\begin{array}{c}\Delta t_{s j} \text { using } \Delta H\left(t_{j}\right) \text { and } \\
H\left(t_{j}\right)\end{array}$ & $\begin{array}{c}t_{j}=t_{j-1}+\Delta t_{s j}, \text { and } H\left(t_{j}\right) \\
=H\left(t_{j-1}\right)-\Delta H\left(t_{j}\right)\end{array}$ \\
\hline Application 2 & $\begin{array}{c}\text { Measured } H_{i n}, H\left(t_{j}\right), t_{j}, \\
\text { assumed } K_{s i} \text { and } \Psi_{i}\end{array}$ & $\begin{array}{c}\Delta t_{s j} \text { using } H\left(t_{j}\right) \text {, and } \\
\Delta H\left(t_{j}\right)\end{array}$ & $\begin{array}{c}\text { NSE between } \Delta t_{s j} \text { and } \\
\Delta t_{j}=t_{j}-t_{j-1}\end{array}$ \\
\hline Application 3 & $\begin{array}{c}\text { Measured } H_{i n}, H\left(t_{j}\right), t_{j}, \\
\text { assumed } K_{s i} \text { and } \Psi_{i}\end{array}$ & $\Delta H_{s}\left(t_{j}\right)$ using $H\left(t_{j}\right)$, and & $\begin{array}{c}\text { NSE between } \Delta H_{s}\left(t_{j}\right) \\
\text { and } \Delta H\left(t_{j}\right)\end{array}$ \\
\hline
\end{tabular}

In Application 1, the forward-modeling code is used to develop a synthetic drawdown data $\left(H\left(t_{j}\right)\right.$ versus $t_{j}$ ), using Equation (6) that was obtained by Ahmed et al. [2], if the soil hydraulic properties ( $K_{s}$ and $\Psi$ ) and the initial value of head $H_{i n}$ are known, and $\Delta H\left(t_{j}\right)$ are then assumed. The water height drop $\Delta H\left(t_{j}\right)$ could be assumed to have constant value (we have used $1 \mathrm{~cm}$ in this study, this value is free to be selected by the user). The code will then compute $H\left(t_{j}\right)=H\left(t_{j-1}\right)-\Delta H\left(t_{j}\right)$ with $H\left(t_{0}\right)=H_{\text {in }}$ or $H\left(t_{j}\right)=H_{\text {in }}-j \times \Delta H\left(t_{j}\right)$ since $H\left(t_{j}\right)$ is necessary for solving $R\left(t_{j}\right)$ using Equation (1) and then determines $\Delta R\left(t_{j}\right)$. Then Equation (6) is used to determine $\Delta t_{s j}$ from which we can estimate $t_{j}=t_{j-1}+\Delta t_{s j}$. Note in this type of purely forward application (namely Application 1) one must assume initial head $H_{\text {in }}$ and $\Delta H\left(t_{j}\right)$ values and use Equation (6) to find $\Delta t_{s j}$. One cannot assume initial 
time and $\Delta t_{j}$ and employ Equation (5) to compute $H\left(t_{s j}\right)$ because the right-hand side of Equation (5) has $H\left(t_{j}\right)$ (which is the values we are trying to estimate), whereas the right-hand side of Equation (6) does not require the values of $t_{j}$. Also, $H\left(t_{j}\right)$ values are required to determine $R\left(t_{j}\right)$ using Equation (1) because the right-hand side of Equation (5) and (6) has $R\left(t_{j}\right)$.

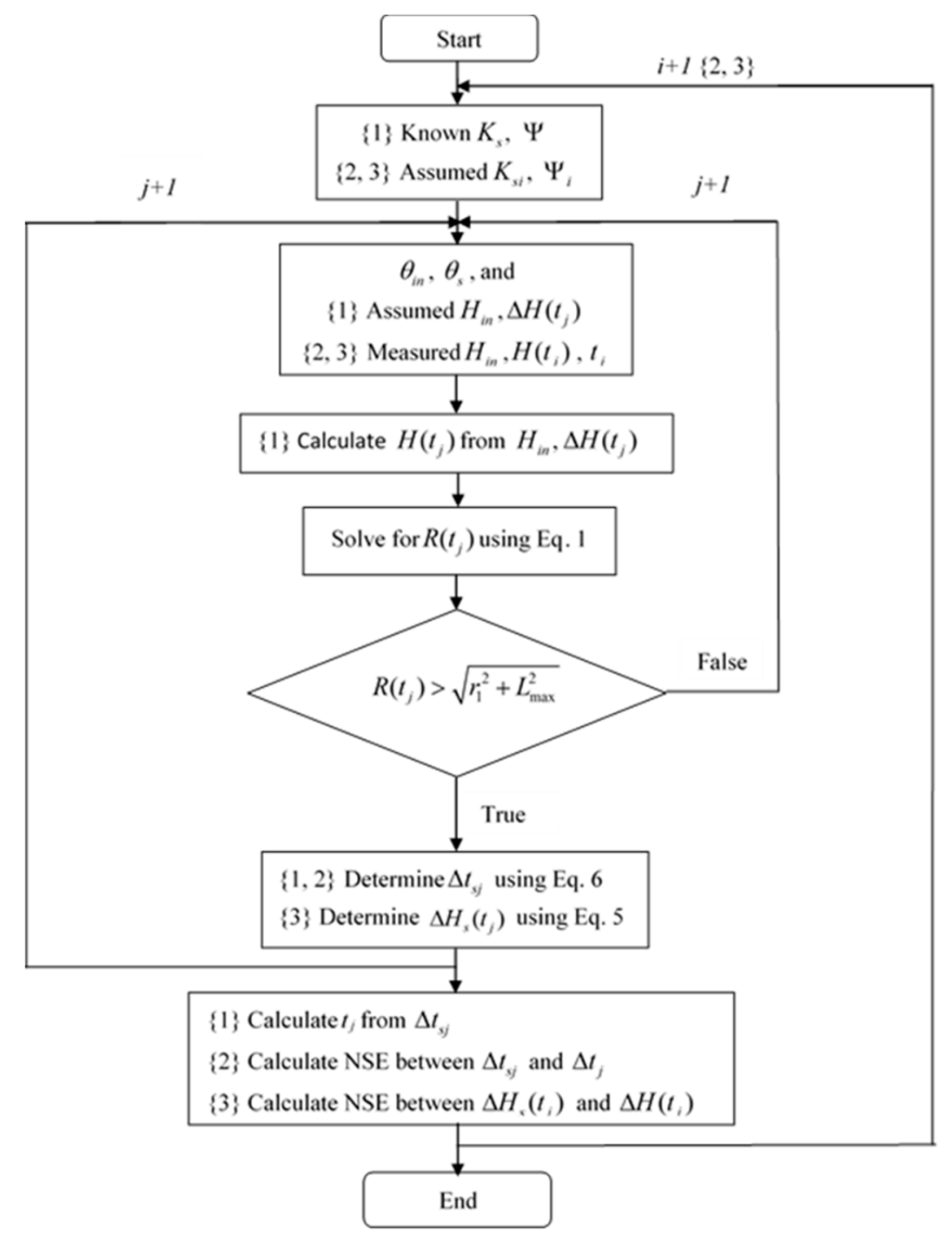

Figure 2. Flowchart for the analysis procedure using the forward-modeling code used to generate the drawdown data and to estimate $K_{s}$ and $\Psi$ for values from measurements of head $H\left(t_{j}\right)$ versus time $t_{j}$. Note: Between \{\} is the application number (e.g., Application 1, 2, and/or 3) that the corresponding parameter or a step is only used for that application/applications.

For Application 2 and 3, we used field infiltration measurement data collected using the MPDI method for three different soil textures. The MPDI was inserted $5 \mathrm{~cm}$ into the soil surface and was rapidly filled with water to an initial height $H_{i n}$. The changes of water height inside the tube $H\left(t_{j}\right)$ was recorded with time $\left(t_{j}, j=1,2, \ldots, n\right)$. The soil moisture content prior the test was measured by collecting soil samples from three different locations around the tube. The soil moisture content after the test was also measured by collecting three different soil samples from the location where the tube was inserted. These soil moisture measurements were made gravimetrically in accordance with the test method ASTM-D2216-10 [34]. Then the soil bulk density was measured closely following the procedure described in ASTM-F1815-11 [35] to convert the gravimetric moisture content into the volumetric soil moisture content. 
The sensitivity of the MPDI theory for predicting $\Delta t_{s j}$ (using Equation (6), which is our Application 2) or for predicting $\Delta H_{s}\left(t_{j}\right)$ (using Equation (5), which is our Application 3) for various values of $K_{s}$ and $\Psi$ was evaluated. For the applications 2 and 3, the field-measured water height $H\left(t_{j}\right)$ inside the tube was used in the model. To understand the sensitivity, we randomly generated a large number of datasets (e.g., $m=30,000$ used in this study) to test different sets of parameters $K_{s i}$ and $\Psi_{\mathrm{i}}(i=1,2, \ldots, m)$ then the drawdown data were predicted for each set. The predicted drawdown data using each set of parameters $K_{s}$ and $\Psi$ were compared with the measured drawdown data to determine what values of $K_{s}$ and $\Psi$ are acceptable. The field recorded measurements for the drop of water height inside the MPDI with time, i.e., $H\left(t_{j}\right)$ and $t_{j}(j=1,2, \ldots, n)$ were used as a part of input data (see Figure 2) in the sensitivity study.

The two soil parameters of the MPDI model were sampled randomly using a uniform distribution within the range of $1 \times 10^{-4} \mathrm{~cm} / \mathrm{s}$ to $1 \times 10^{-1} \mathrm{~cm} / \mathrm{s}$ and $-85 \mathrm{~cm}$ to $-1 \mathrm{~cm}$ for $K_{s}$ and $\Psi$, respectively; these ranges include all the soil types as reported in Clapp and Hornberger [36]. Note the value of $\Psi$ will also be a function of the moisture content and it can vary with the soil type. The total 30,000 sets of generated parameters were checked graphically to make sure that the generated parameter sets cover all possible random combination of $K_{s}$ and $\Psi$ values. The Nash-Sutcliffe efficiency (NSE) [37] was used to rank and evaluate the acceptability of each set of model parameters $K_{s}$ and $\Psi$. For Application 2 , predicted $\Delta t_{s j}$ and measured $\Delta t_{j}=t_{j}-t_{j-1}$ were compared to compute the NSE value; note that the forward-modeling code outputs modeled $\Delta t_{s j}$ between the measured water heights $H\left(t_{j}\right)$. For Application 3, predicted $\Delta H_{s}\left(t_{j}\right)$ and measured $\Delta H\left(t_{j}\right)=H\left(t_{j}\right)-H\left(t_{j-1}\right)$ were compared to compute the NSE value. In this case, the forward-modeling code outputs modeled $\Delta H_{s}\left(t_{j}\right)$ at measured water height $\Delta H\left(t_{j}\right)$ and $\Delta t_{j}$ for $\Delta H\left(t_{j}\right)=H\left(t_{j}\right)-H\left(t_{j-1}\right)$.

A detailed flowchart for the analysis procedure used in the forward model is shown in Figure 2 for all the three applications (also see Table 1). The Newton-Raphson's method was used to solve for the wetting front radius $R\left(t_{j}\right)$ using the mass balance relation (Equation (1)). To evaluate the quality of the fit, the NSE values could be calculated between simulated and measured values of $\Delta t_{j}, \Delta H\left(t_{j}\right), t_{j}$, or $H\left(t_{j}\right)$. However, to be consistent with the analysis procedure introduced by Ahmed et al. [2], $\Delta t_{j}$ and $\Delta H\left(t_{j}\right)$ data were used in this study to determine the NSE values. The NSE was calculated only for data when the MPDI analysis is valid, i.e., $R\left(t_{j}\right)>\sqrt{r_{1}^{2}+L_{\text {max }}^{2}}$.

\section{Results and Discussion}

\subsection{Example of the Use of Application 1: Forward Simulation of Drawdown Curves for Different Types of Soil}

The forward-modeling code was used to predict the drawdown curves of the MPDI (Application 1), using Equation (6) that was obtained by Ahmed et al. [2], for three types of soils using the soil properties reported by Rawls et al. [38]. To show the variations of the drawdown curves predicted using the MPDI theory, at varying soil hydraulic properties, three types of soil (silt loam, sandy loam, and sand, see Table 2) were considered. Following the procedure for Application 1 described in the methods section, $H_{\text {in }}$ was assumed as $51 \mathrm{~cm}$, and $\Delta H\left(t_{j}\right)$ as $1.0 \mathrm{~cm}(j=2,3, \ldots, n)$. The moisture deficit $\Delta \theta$ was assumed to be the same for all the three soils and fixed at 0.05 (assumed wet soil). Then at $\Delta \theta_{\max }$ (assumed dry soil) for each soil when $\theta_{\text {in }}$ was set at the field capacity (minimum $\theta$ ) and $\theta_{s}$ at the saturated moisture content or effective porosity (see Table 2). The Brook and Corey model [39] was used to determine $\Psi$ for each $\theta_{\text {in }}$ value and the results are summarized in Table 2. Note, in Table 2, $\theta_{r}$ is the residual saturation, $\theta_{e}$ is the effective porosity, $\Psi_{\mathrm{b}}$ is the bubbling pressure, and $\lambda$ is the pore size distribution; the values reported were selected from the ranges recommended by Rawls et al. [38]. 
Table 2. The soil hydraulic properties for silt loam, sandy loam, and sand [38] and statistical summary of predicted $\Delta t_{s j}$ (seconds).

\begin{tabular}{|c|c|c|c|c|c|c|c|c|c|c|c|}
\hline \multirow[t]{2}{*}{ Soil Type } & \multirow{2}{*}{$\begin{array}{c}K_{s}{ }^{a} \\
(\mathrm{~cm} / \mathrm{s})\end{array}$} & \multirow[t]{2}{*}{$\theta_{r}^{a}$} & \multirow[t]{2}{*}{$\theta_{e}^{a}$} & \multirow{2}{*}{$\begin{array}{l}\Psi_{b}{ }^{a} \\
(\mathrm{~cm})\end{array}$} & \multirow[t]{2}{*}{$\lambda^{a}$} & \multirow{2}{*}{$\begin{array}{c}\Delta \theta^{b} \\
\theta_{e}-\theta_{i n}\end{array}$} & \multirow{2}{*}{$\begin{array}{l}\Psi^{c} \\
(\mathrm{~cm})\end{array}$} & \multicolumn{4}{|c|}{$\Delta t_{s j}$ (Seconds) } \\
\hline & & & & & & & & $\operatorname{Max}$ & Min & Avg & SD \\
\hline \multirow{2}{*}{ Silt loam } & \multirow{2}{*}{$1.89 \times 10^{-4}$} & \multirow{2}{*}{0.027} & \multirow{2}{*}{0.501} & \multirow{2}{*}{-17} & \multirow{2}{*}{0.36} & 0.050 (wet) & -24 & 1615 & 526 & 899 & 302 \\
\hline & & & & & & 0.217 (dry) & -86 & 459 & 274 & 361 & 53 \\
\hline \multirow{2}{*}{ Sandy loam } & \multirow{2}{*}{$7.19 \times 10^{-4}$} & \multirow{2}{*}{0.025} & \multirow{2}{*}{0.412} & \multirow{2}{*}{-15} & \multirow{2}{*}{0.61} & 0.050 (wet) & -19 & 530 & 148 & 270 & 104 \\
\hline & & & & & & 0.222 (dry) & -61 & 169 & 88 & 124 & 23 \\
\hline \multirow[t]{2}{*}{ Sand } & \multirow[t]{2}{*}{$5.83 \times 10^{-3}$} & \multirow{2}{*}{0.010} & \multirow{2}{*}{0.417} & \multirow{2}{*}{-8} & \multirow[t]{2}{*}{1.09} & 0.050 (wet) & -9 & 123 & 21 & 47 & 26 \\
\hline & & & & & & 0.355 (dry) & -53 & 23 & 12 & 17 & 3 \\
\hline
\end{tabular}

${ }^{\mathrm{a}}$ Data from Rawls et al. [38]; ${ }^{\mathrm{b}}$ Assumed small and maximum soil moisture deficits; ${ }^{\mathrm{c}}$ Determined for every $\theta_{\text {in }}$ value using the Brook and Corey model [39].

The forward-modeling code considers that the MPD theory is only valid when the geometric shape of the wetting front remains constant at the sphere; typically, at $R\left(t_{j}\right)$ values greater than $\sqrt{r_{1}^{2}+L_{\text {max }}^{2}}$. The corresponding first water height $H\left(t_{1}\right)$ when the MPDI theory is valid can be computed from Equation (1), which is the mass balance equation for determining necessary water needed to satisfy a given moisture deficit $\Delta \theta=\theta_{s}-\theta_{\text {in }}$.

$$
\begin{aligned}
& \Delta H_{1}=H_{\text {in }}-H\left(t_{1}\right)=16.928 \Delta \theta \\
& \text { when } R\left(t_{1}\right)=\sqrt{r_{1}^{2}+L_{\text {max }}^{2}}=2 \sqrt{5} \mathrm{~cm} \quad \text { since } r_{1}=L_{\max }=5 \mathrm{~cm}
\end{aligned}
$$

Equation (7) clearly shows that the first water height or head drop $\Delta H_{1}$ after which the model starts to be valid is independent of the soil texture class (not related to $K_{S}$ and $\Psi$ ) but only depends on $\Delta \theta$. When assuming $H_{\text {in }}$ is equal to $51.0 \mathrm{~cm}$ and $\Delta H\left(t_{j}\right)$ as $1.0 \mathrm{~cm}(j=2,3, \ldots, n)$, and when the value of $\Delta \theta=\theta_{s}-\theta_{\text {in }}$ was set to be the same value for all the three types of soil at 0.05 (wet soil), the calculated $\Delta H_{1}$ values for all the three soils is found to be $0.8 \mathrm{~cm}$. Therefore, the water height $H\left(t_{1}\right)$ at which the Modified Philip-Dunne model starts to be valid for silt loam, sandy loam, and sand is 50.2 $\mathrm{cm}$. When we used $\Delta \theta_{\max }$ (assuming dry soil) values of $0.217,0.222$, and 0.355 , the calculated $\Delta H_{1}$ values are 3.7, 3.8, and $6.0 \mathrm{~cm}$ for silt loam, sandy loam, and sand, respectively. Therefore, the water height $H\left(t_{1}\right)$ at which the MPDI model starts to be valid for silt loam, sandy loam, and sand are 47.3 $\mathrm{cm}, 47.2 \mathrm{~cm}$, and $45.0 \mathrm{~cm}$, respectively.

The corresponding results of the drawdown curves are given in Figure 3, which starts from $H\left(t_{1}\right)$ to 0 . When $\Delta \theta$ was assumed the same for all the soil types at 0.05 (wet soils), the total drawdown time $t_{n}$ of $H\left(t_{1}\right)=50.2 \mathrm{~cm}$ water within the MPDI for silt loam, sandy loam, and sand were predicted as $45011.3 \mathrm{sec}(750.2 \mathrm{~min}), 13531.6 \mathrm{sec}(225.5 \mathrm{~min})$, and $2353.3 \mathrm{sec}(39.2 \mathrm{~min})$, respectively. When the forward-modeling code was applied for $\Delta \theta_{\max }$ of each soil (dry conditions), the total drawdown time $t_{n}$ of $H\left(t_{1}\right)=47.3,47.2$, and $45.0 \mathrm{~cm}$ water within the MPDI for silt loam, sandy loam, and sand were predicted as $17028.9 \mathrm{sec}(283.8 \mathrm{~min}), 5843.9 \mathrm{sec}(97.4 \mathrm{~min})$, and $755.3 \mathrm{sec}(12.6 \mathrm{~min})$, respectively. Statistical summary (maximum, minimum, average, and standard deviation) of predicted $\Delta t_{s j}$ for each $1.0 \mathrm{~cm}$ drop is listed in Table 2 for each soil. The smallest $\Delta t_{s j}$ occurs at the earliest drawdown interval and the largest $\Delta t_{s j}$ at the last drawdown interval.

The total drawdown time $t_{n}$ values needed to infiltrate $H\left(t_{1}\right) \mathrm{cm}$ water within the MPDI are 57 to $68 \%$ shorter when $\Delta \theta$ was assumed the same for all the soil types at 0.05 (wet soils) than when $\Delta \theta_{\max }$ (dry soils) was assumed. Please note that $H\left(t_{1}\right)$ values are different when $\Delta \theta_{\max }$ and $\Delta \theta=0.05$ were assumed for every soil type; therefore, the time needed to infiltrate the first drawdown $\Delta H_{1}$ was excluded from the calculation since the Modified Philip-Dunne theory is not valid. This means that the total drawdown time $t_{n}$ needed to infiltrate $H\left(t_{1}\right) \mathrm{cm}$ water from the MPDI into wet soil is much more than the time need to infiltrate into dry soil. This is similar to the observations from previous studies that showed that the rate at which water infiltrates into dry soil can be higher than wet soil [40-42]. 


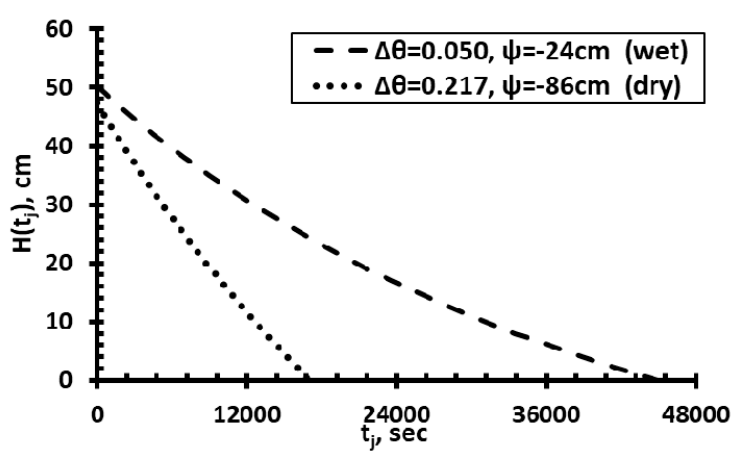

(a) Silt loam

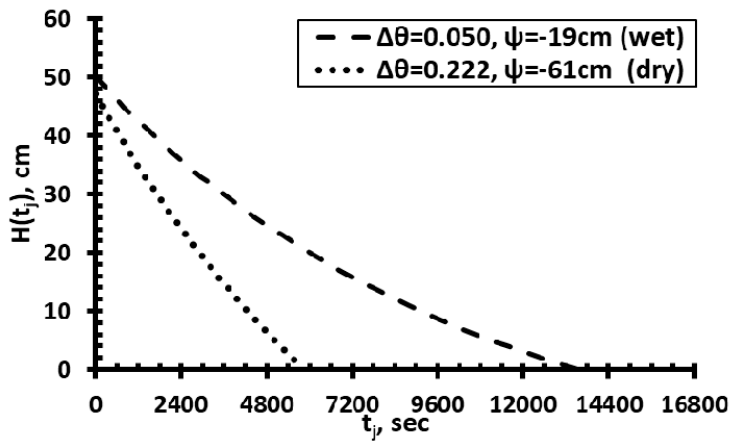

(b) Sandy loam

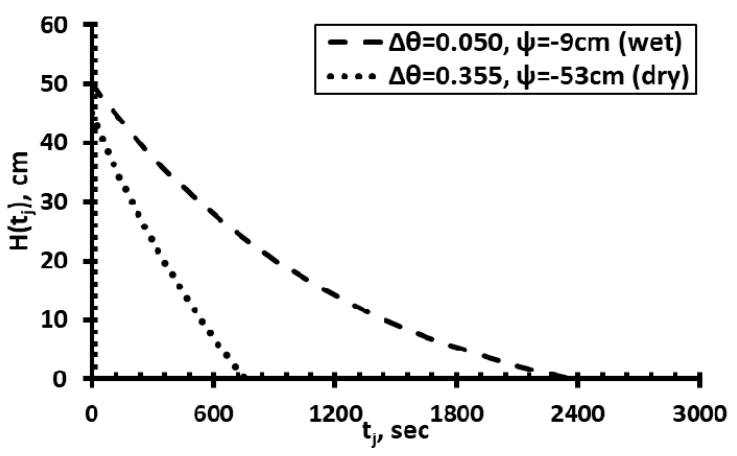

(c) Sand

Figure 3. Drawdown curves for (a) silt loam, (b) sandy loam, and (c) sand estimated by the forward-modeling code using the soil properties $K_{s}$ and $\Psi$ reported in Table 2 for two different values of $\Delta \theta$ representing wet and dry conditions. Three graphs $(\mathbf{a}-\mathbf{c})$ have different scales for the $\mathrm{x}$-axis (time in sec).

Since $H\left(t_{1}\right)$ values are different as it depends on the assumed value of $\Delta \theta$ and to facilitate an easy comparison, the time $t_{n}$ needed to infiltrate $45.0 \mathrm{~cm}$ (the height at which the model is valid for the three soils) water inside the MPDI was determined for all the three soil types. When $\Delta \theta_{\max }$ was assumed, $t_{n}$ were predicted as 16,392.0 sec (273.2 $\mathrm{min}), 5644.9 \mathrm{sec}(94.1 \mathrm{~min})$, and $755.3 \mathrm{sec}(12.6 \mathrm{~min})$ for silt loam, sandy loam, and sand, respectively. The corresponding total drawdown time when $\Delta \theta=0.05$ were also calculated as 42,220.3 $\mathrm{sec}(703.7 \mathrm{~min}), 12742.7 \mathrm{sec}(212.4 \mathrm{~min})$, and $2239.7 \mathrm{sec}(37.3 \mathrm{~min})$ for silt loam, sandy loam, and sand systems, respectively. For each of the three soil, the total drawdown time for $45.0 \mathrm{~cm}$ of water under $\Delta \theta_{\max }$ is 56 to $66 \%$ shorter than one observed using $\Delta \theta=0.05$, but the total drawdown time for silt loam is about 20 times larger than one observed for the sand system.

\subsection{Example of the Use of Application 2: Simulation Using $\Delta t_{s j}$ Determined by Equation (6) and Compare with the Measured Time Intervals $\Delta t_{j}$}

A field-measured drawdown data $\left[H\left(t_{j}\right)\right.$ versus $\left.t_{j}\right]$ were collected using the MPDI for three types of soil (silt loam, sandy loam, and sand). The data for sandy loam were collected in an infiltration basin in Stillwater, Minnesota and provided by Farzana Ahmed [43]. The data for silt loam and sand were collected in an agriculture experimental field and a pile of construction sand, respectively, in Auburn, Alabama. These three soils were selected to represent a relatively wide range of low to high $K_{s}$ and $\Psi$ values.

The collected data were used in the sensitivity analysis procedure, which uses the forward-modeling code for Application 2 as described in the flowchart (see Figure 2). For every set of the 30,000 randomly generated parameters, the drawdown curves similar to Figure 3 were developed and the NSE values were then calculated using $\Delta t_{s j}$ determined by Equation (6) and the measured time intervals $\Delta \mathrm{t}_{\mathrm{j}}$. Even though the two soil parameters $K_{s}$ and $\Psi$ were sampled 30,000 times randomly using a uniform distribution in the range $1 \times 10^{-4} \mathrm{~cm} / \mathrm{s}$ to $1 \times 10^{-1} \mathrm{~cm} / \mathrm{s}$ and $-85 \mathrm{~cm}$ to 
$-1 \mathrm{~cm}$, respectively, Figure 4 only shows the sets of parameters with NSE values greater than zero, which are $3.4 \%, 32.2 \%$, and $16.2 \%$ of the 30,000 sets of parameters for silt loam, sandy loam, and sand, respectively. Figure 4 clearly indicates that a large number of the randomly generated parameters $K_{s}$ and $\Psi$ combinations for each type of soil produced the drawdown curves that did not match well (NSE $<0)$ with the corresponding observed drawdown data. For example, the x-axes of Figure 4 for the three soils have different scales $(0.005,0.05$, and 0.5$)$ for $K_{s}$ in $\mathrm{cm} / \mathrm{s}$, all parameter combinations with $K_{s}$ $>0.0018 \mathrm{~cm} / \mathrm{s}$ for silt loam (Figure $4 \mathrm{a}$ ), $K_{s}>0.01 \mathrm{~cm} / \mathrm{s}$ for sandy loam (Figure $4 \mathrm{~b}$ ), and $K_{s}>0.082 \mathrm{~cm} / \mathrm{s}$ for sand (Figure 4c) would produce drawdown curves with NSE $<0$ in comparison to the measured drawdown data. It means that the Modified Philip-Dunne theory can eliminate any unrealistic $K_{s}$ but not for $\Psi$ since the full range of $\Psi$ would produce drawdown curves with NSE $>0$ as long as $K_{S}$ is within a reasonable range (Figure 4). This is an important conclusion of the study. Therefore, we used wide ranges for $K_{s}$ and $\Psi$ to randomly generate 30,000 parameter sets; if narrow rages were used, it may not allow us to obtain this important result.
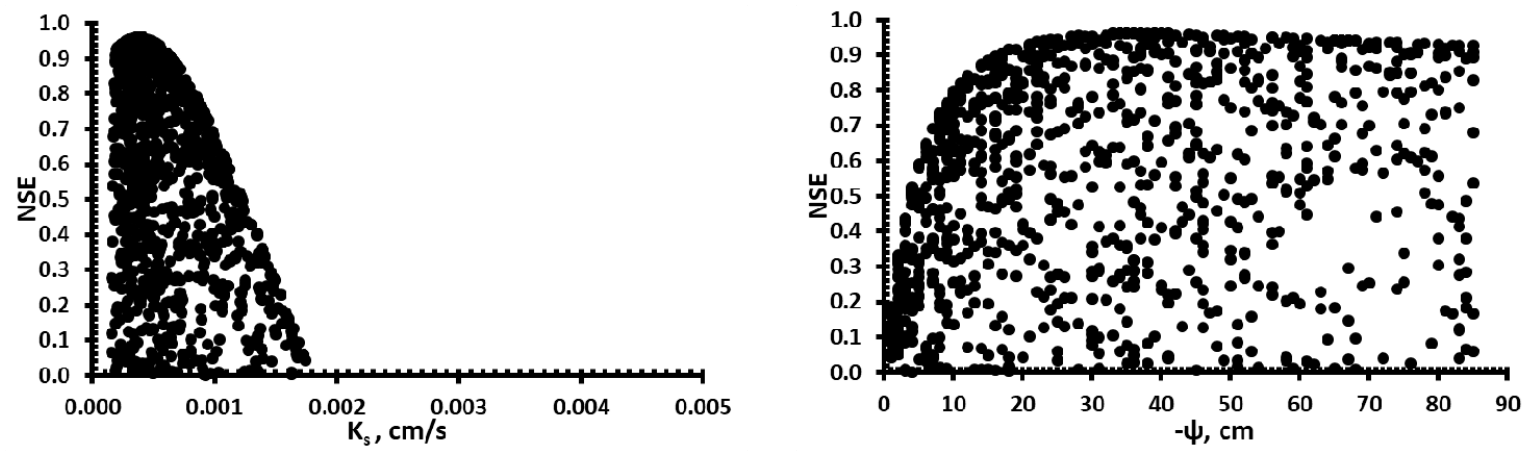

(a) Silt loam
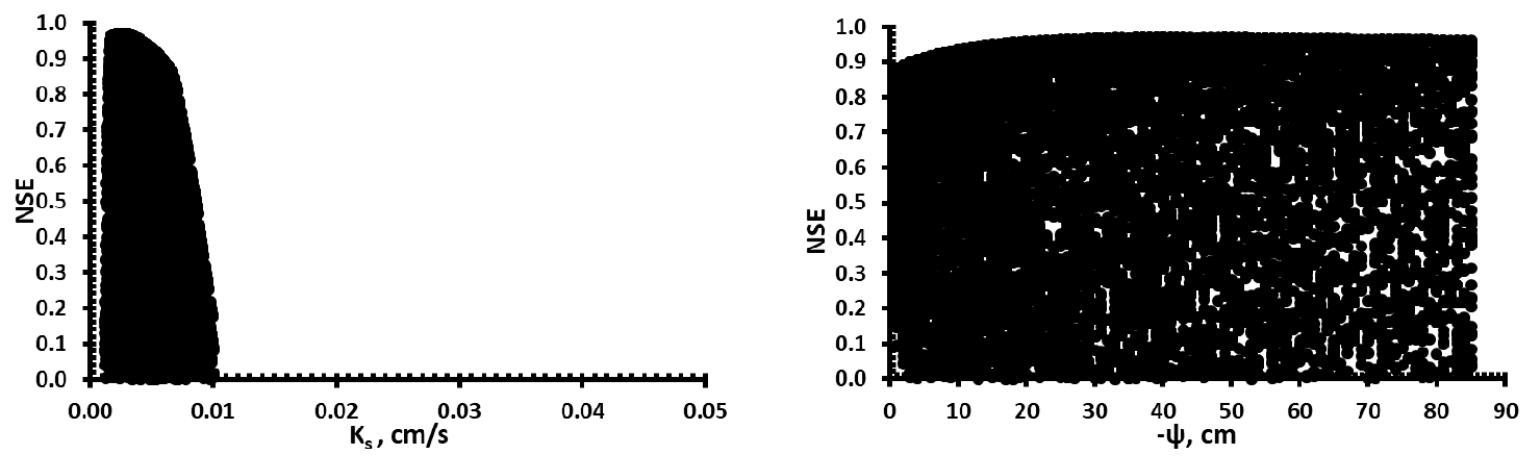

(b) Sandy loam
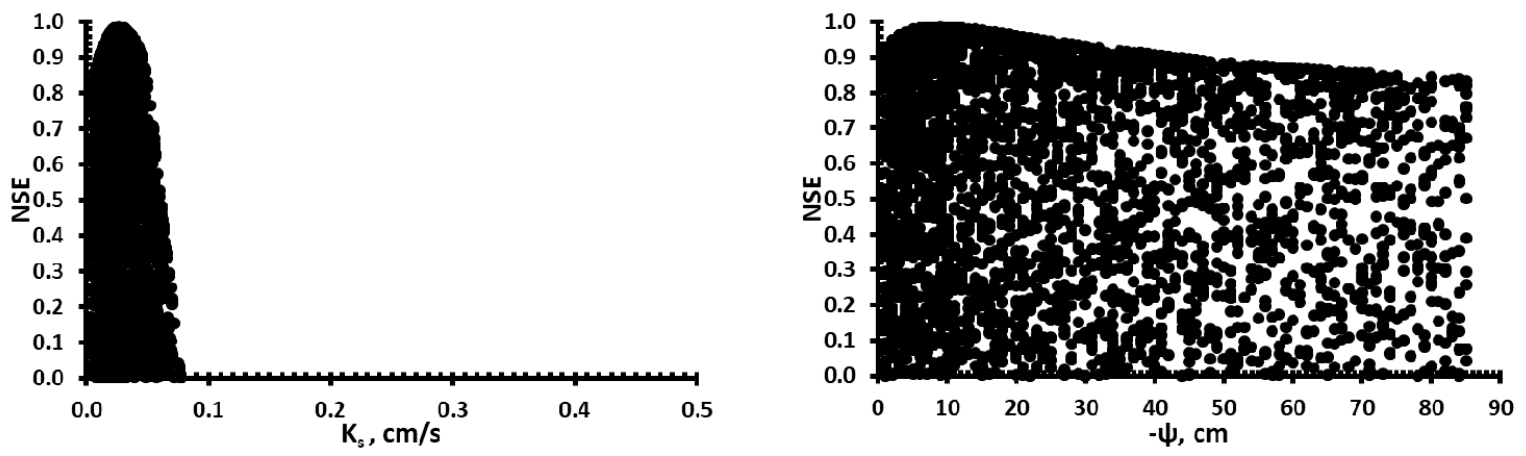

(c) Sand

Figure 4. Scatter plots for the NSE calculated between $\Delta t_{s j}$ determined by Equation (6) and the measured time intervals $\Delta \mathrm{t}_{\mathrm{j}}$, on the left is NSE versus $K_{s}(\mathrm{~cm} / \mathrm{s})$ and NSE versus - $\Psi(\mathrm{cm})$ is on the right. (a) silt loam, (b) sandy loam, and (c) sand. The scales for $K_{s}$ are different for each of the three soils. 
Figure 4 shows that the saturated hydraulic conductivity $K_{s}$ is strongly correlated with the NSE but the Green-Ampt suction head $\Psi$ at the wetting front is not. The highest NSE values for the most optimal set of parameters are $0.961,0.968$, and 0.986 for silt loam, sandy loam, and sand, respectively. An NSE threshold was adopted to delineate the successful sets of parameters (Figure 5) that produce the drawdown curve matching well with the observed drawdown data. The NSE threshold were determined as a ratio ( 0.98 was used in this study) of the highest NSE values of the most optimal set of parameters. The selected NSE thresholds were checked and show a well matching with the field-measured drawdown data for all the three types of soil (Figure 5). Please note that we have not used a fixed NSE (e.g., 0.9 or 0.95 ) as threshold to identify the successful sets of parameters since NSE also depends on which variable (e.g., $\Delta t_{j}$ or $\Delta H_{j}$ ) is used to compute NSE (see Section 3.3), and the range between the highest NSE and the fixed threshold may vary for each test based on the value of the highest NSE.

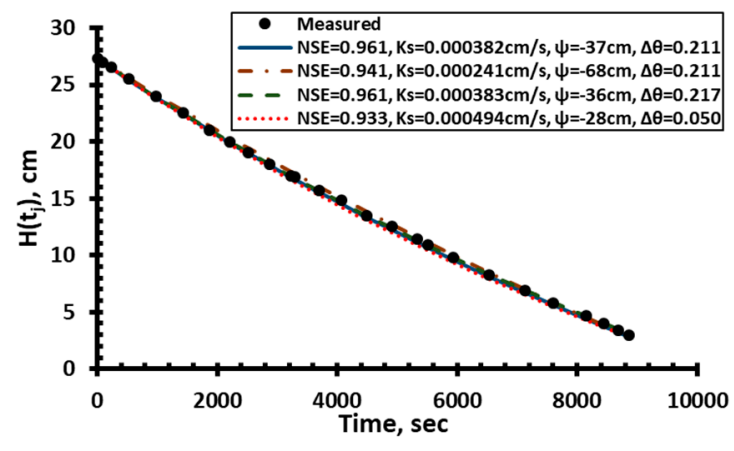

(a) Silt loam

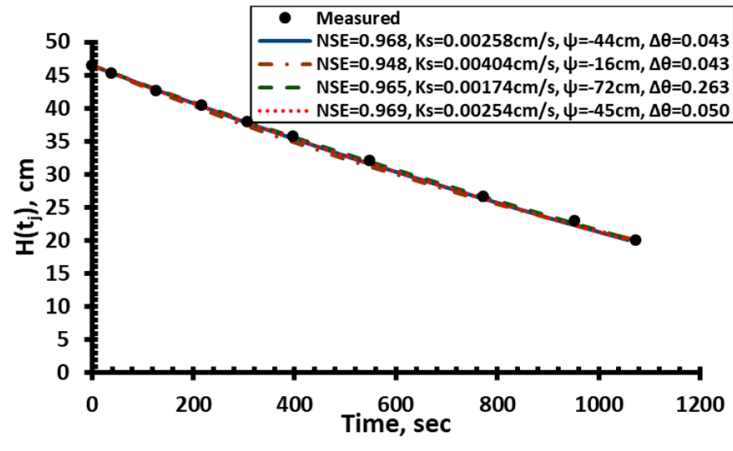

(b) Sandy loam

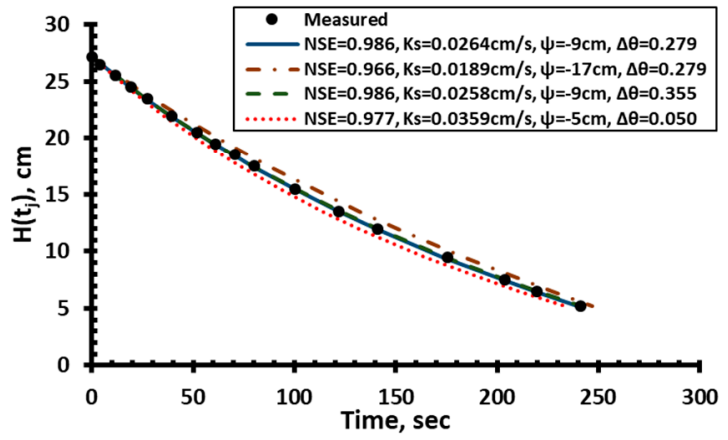

(c) Sand

Figure 5. The field-measured and the simulated drawdown curves using the sets of parameters with the highest and threshold NSE values (determined using $\Delta t$ ) and for $K_{S}$ and $\Psi$ back-fitted using two assumed $\Delta \theta$ values: (a) silt loam, (b) sandy loam, and (c) sand. Note, the dots show measured drawdown data, the blue lines give the drawdown curves with the highest NSE (e.g., 0.961 for silt loam), and brown dash-dotted lines give the drawdown curves with the selected NSE threshold (e.g., $0.941=0.98 \times 0.961$ for silt loam).

The successful values of $K_{s}$ (with NSE $\geq$ the threshold) are ranged within the same order of magnitude that are consistent with the tested soil texture class: $2.4-5.3 \times 10^{-4} \mathrm{~cm} / \mathrm{s}, 1.6-4.3 \times 10^{-3} \mathrm{~cm} / \mathrm{s}$, and 1.9-3.5 $\times 10^{-2} \mathrm{~cm} / \mathrm{s}$ for silt loam, sandy loam, and sand, respectively (Figure 6). Previous studies have shown that the measured $K_{s}$ values may vary among the measurement methods by two or more orders of magnitude [26,44]. 


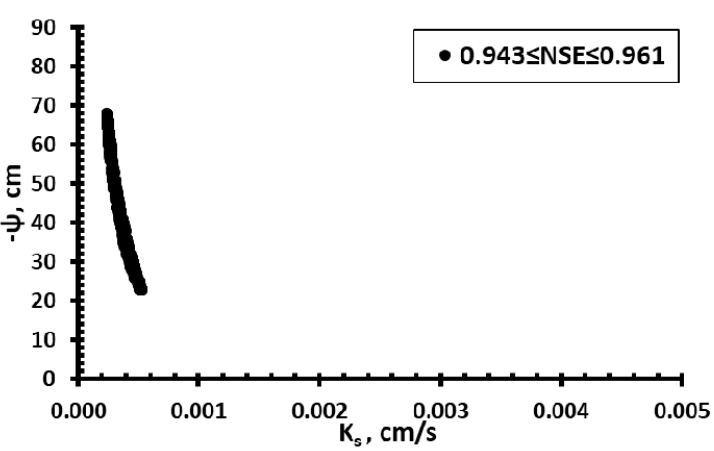

(a) Silt loam

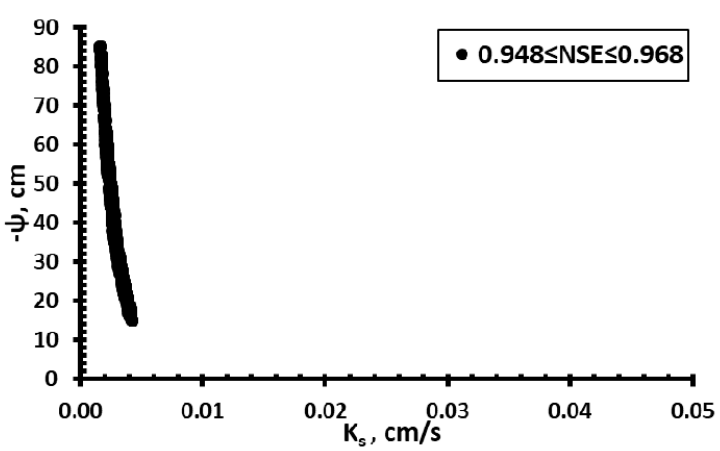

(b) Sandy loam

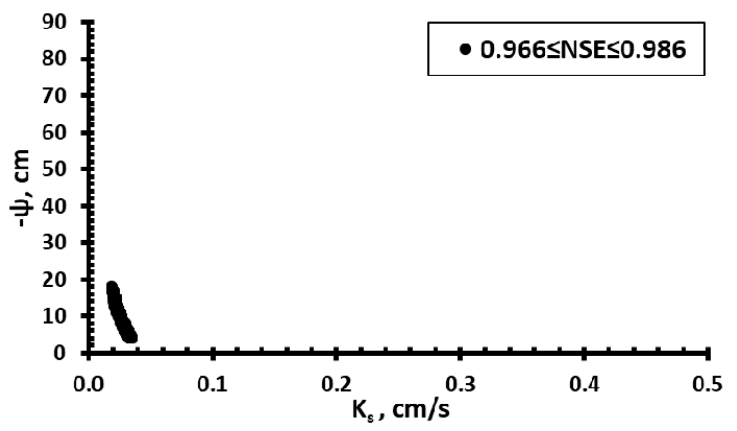

(c) Sand

Figure 6. The successful sets of parameters $K_{S}$ versus $-\Psi$ (delineated by NSE $\geq$ the threshold value) determined from simulation using $\Delta t_{s j}$ determined by Equation (6) and the measured time intervals $\Delta \mathrm{t}_{\mathrm{j}}$ : (a) silt loam, (b) sandy loam, and (c) sand. Note: The limits for $K_{s}$ (or x-axis) are different for the three soils.

On the other hand, the successful $\Psi$ (with NSE $\geq$ the threshold) values do not converge to a specific range as in the case of $K_{s}$. The $\Psi$ values ranged between $-68 \mathrm{~cm}$ and $-23 \mathrm{~cm},-85 \mathrm{~cm}$ and $-15 \mathrm{~cm}$, and -18 and -4 for silt loam, sandy loam, and sand, respectively (Figure 6). The successful sets of parameters $K_{S}$ and $\Psi$ (with NSE $\geq$ the threshold) for the three types of soil are plotted together in Figure 6.

The most optimal set of parameters (with the highest NSE values) determined using Application 2 and 3 (see Section 3.3) are reported in Table 3. Using the backward-fitting analysis procedure introduced by Ahmed et al. [2], the fitted optimal parameters of $K_{s}$ and $\Psi$ using $\Delta \mathrm{t}_{\mathrm{j}}$ are $3.96 \times 10^{-4}$ $\mathrm{cm} / \mathrm{s}$ and $-37 \mathrm{~cm}$ for silt loam with NSE of $0.961 ; 2.59 \times 10^{-3} \mathrm{~cm} / \mathrm{s}$ and $-44 \mathrm{~cm}$ for sandy loam with NSE of 0.968 ; and $2.66 \times 10^{-2} \mathrm{~cm} / \mathrm{s}$ and $-9 \mathrm{~cm}$ for sand with NSE of 0.986 .

Table 3. The most optimal sets of $K_{S}$ and $\Psi$ (with the highest NSE values) determined using Application 2 and 3 as described in the flowchart (see Figure 2) with measured $\Delta \theta, H_{i n}, \theta_{i n}$, and $\theta_{s}$ (input data) for the three tested soils (silt loam, sandy loam, and sand).

\begin{tabular}{ccccccccc}
\hline Soil Type & $\boldsymbol{H}_{\text {in }}$ & $\boldsymbol{\theta}_{\text {in }}$ & $\boldsymbol{\theta}_{\boldsymbol{s}}$ & $\boldsymbol{\Delta} \boldsymbol{\theta}$ & \multicolumn{2}{c}{$\boldsymbol{K}_{\boldsymbol{s}}(\mathbf{c m} / \mathbf{s})$} & \multicolumn{2}{c}{$\boldsymbol{\Psi}(\mathbf{c m})$} \\
\hline & $\mathbf{( c m )}$ & & & & Application 2 & Application 3 & Application 2 & Application 3 \\
\hline Silt loam & 31.0 & 0.238 & 0.449 & 0.211 & $3.82 \times 10^{-4}$ & $3.88 \times 10^{-4}$ & -37 & -36 \\
Sandy loam & 51.0 & 0.339 & 0.382 & 0.043 & $2.58 \times 10^{-3}$ & $2.83 \times 10^{-3}$ & -44 & -37 \\
Sand & 33.5 & 0.096 & 0.375 & 0.279 & $2.64 \times 10^{-2}$ & $2.74 \times 10^{-2}$ & -9 & -8 \\
\hline
\end{tabular}

Please note that all the synthetic drawdown data that were developed following the procedure of Application 1 (data of Figure 3) were also used in the sensitivity analysis procedure, which uses the forward-modeling code for Application 2 as described in the flowchart (see Figure 2). Results were similar to Figures 4-6 determined using the measured drawdown data described earlier in this section. 
3.3. Example of the Use of Application 3: Simulation Using $\Delta H_{s}\left(t_{j}\right)$ Determined by Equation (5) and Compare with the Changes in Measured Head Values $\Delta H\left(t_{j}\right)$

The collected data for the three types of soil were also analyzed using the forward-modeling code of the Application 3 mode (see Figure 2), which is based on estimating $\Delta \mathrm{H}_{\mathrm{s}}\left(\mathrm{t}_{\mathrm{j}}\right)$ determined by Equation (5) and comparing with measured head changes, $\Delta \mathrm{H}\left(\mathrm{t}_{\mathrm{j}}\right)$ values. Figure 7 shows the results out of the 30,000 sets of randomly generated parameters $K_{s}$ and $\Psi$ with corresponding NSE values greater than zero for the three types of soil. The number of parameter sets with NSE $>0$ are $1.8 \%, 12.5 \%$, and $5.0 \%$ of the 30,000 sets of the parameters for silt loam, sandy loam, and sand, respectively.
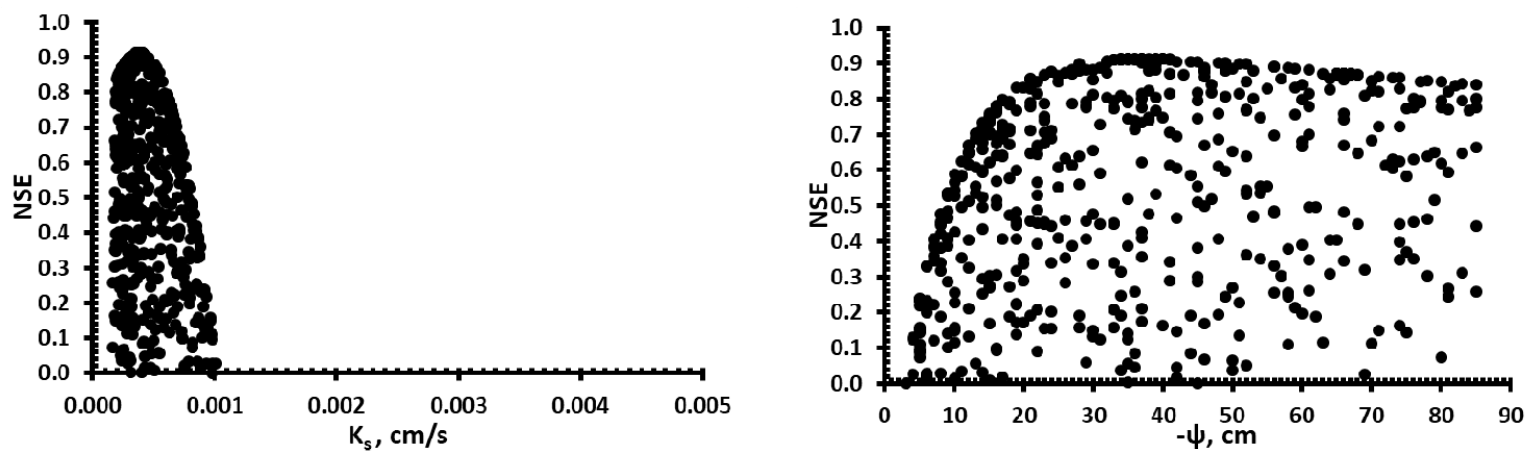

(a) Silt loam
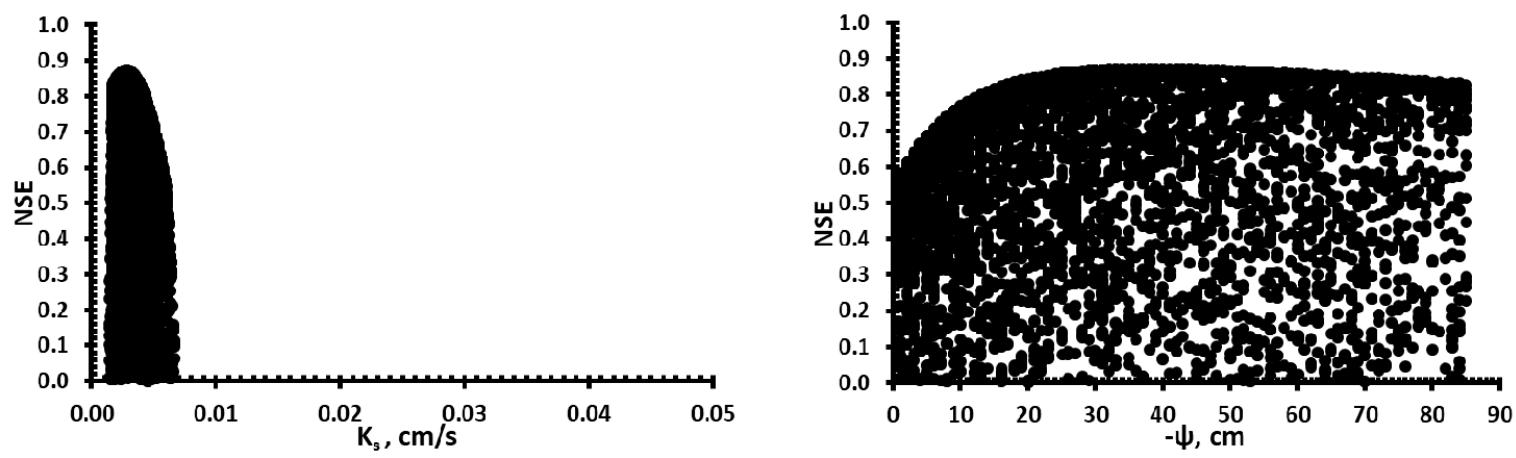

(b) Sandy loam
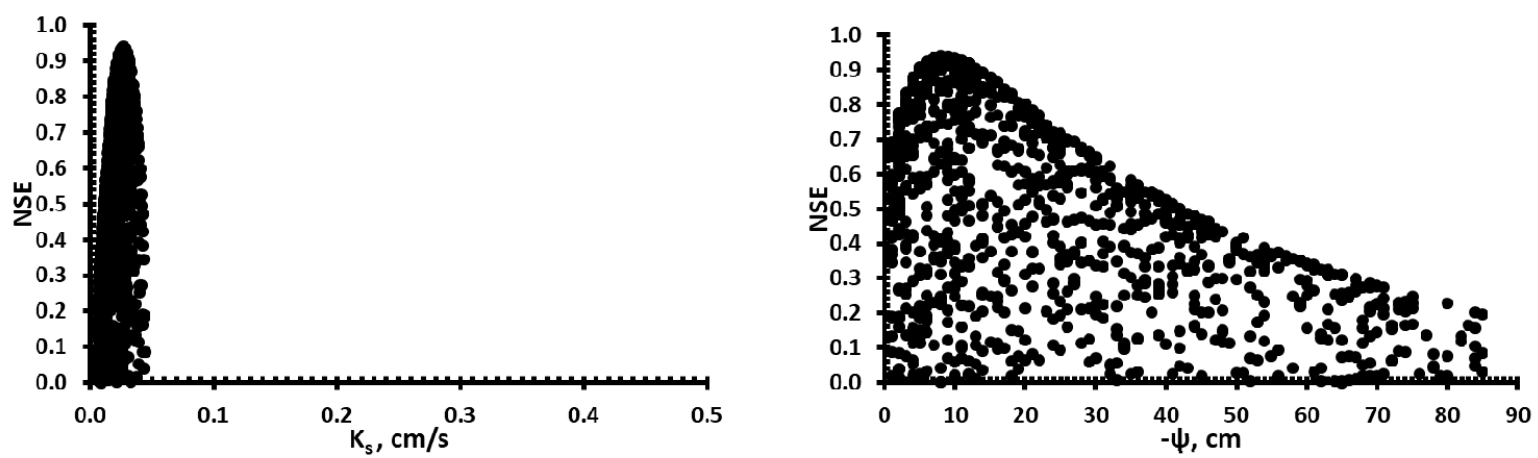

(c) Sand

Figure 7. Scatter plots for the NSE calculated between $\Delta H_{s}\left(t_{j}\right)$ determined by Equation (5) and the changes in measured head $\Delta \mathrm{H}\left(\mathrm{t}_{\mathrm{j}}\right)$, on the left is $K_{S}$ versus NSE and $-\Psi$ versus NSE is on the right. (a) Silt loam, (b) Sandy loam, and (c) Sand.

Results from the simulation using $\Delta H$ supported the strong correlation between NSE and $K_{s}$ and the weak correlation with $\Psi$. The highest NSE values for the most optimal set of parameters are 0.914 , 0.872 , and 0.940 for silt loam, sandy loam, and sand, respectively. The NSE threshold was determined 
using the same ratio (0.98) of the highest NSE value applied in Section 3.2. Please note that the NSE calculated from $\Delta H$ is lower than the NSE calculated from $\Delta t$. This difference comes from the definition of the NSE proposed by Nash and Sutcliffe [37] that is equal to one minus the sum of the absolute squared differences between predicted and observed values normalized by the variance of observed values. The variance of observed $\Delta H_{j}$ is typically less than the variance of $\Delta t_{j}$ (see Figures 3 and 5); therefore, it leads to a lower value of NSE when NSE was determined using $\Delta H_{j}$.

Similar to the results from Section 3.2, the successful values of $K_{S}$ (with NSE $\geq$ the threshold) were ranged within the same order of magnitude that are consistent with the tested soil texture class: $2.9-4.7 \times 10^{-4} \mathrm{~cm} / \mathrm{s}, 2.0-3.5 \times 10^{-3} \mathrm{~cm} / \mathrm{s}$, and $2.4-3.0 \times 10^{-2} \mathrm{~cm} / \mathrm{s}$ for silt loam, sandy loam, and sand, respectively (Figure 8). The successful values of $\Psi$ (with NSE $\geq$ the threshold) still do not converge to a specific range as in the case of $K_{s}$. The successful values of $\Psi$ (with NSE $\geq$ the threshold) ranged between $-52 \mathrm{~cm}$ and $-27 \mathrm{~cm},-64 \mathrm{~cm}$ and $-24 \mathrm{~cm}$, and -11 and -6 for silt loam sandy loam, and sand, respectively (Figure 8).

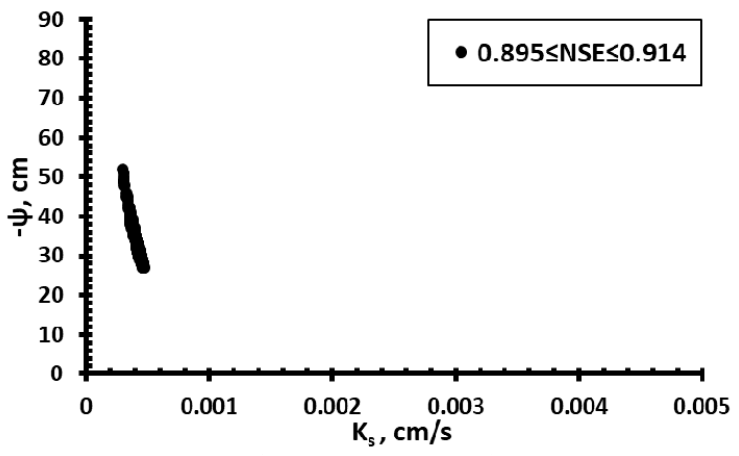

(a) Silt loam

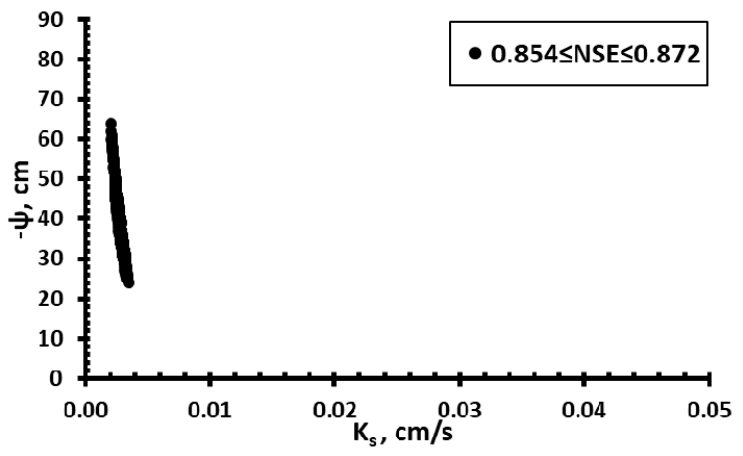

(b) Sandy loam

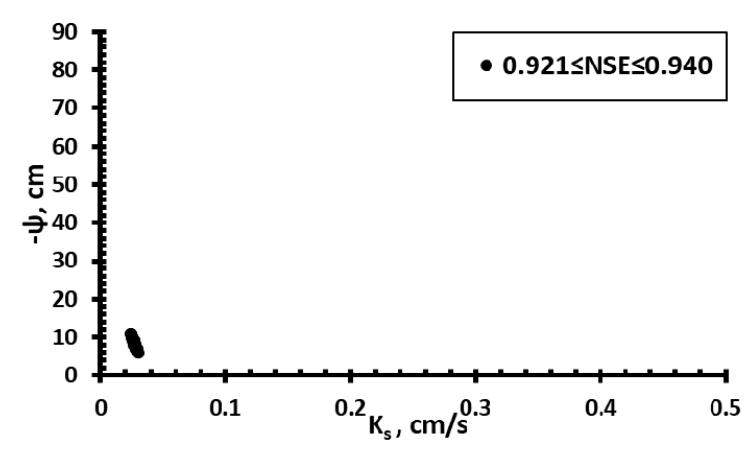

(c) Sand

Figure 8. The successful sets of parameters $K_{s}$ versus - $\Psi$ (delineated by NSE $\geq$ the threshold value) determined from simulation using $\Delta H_{s}\left(t_{j}\right)$ determined by Equation (5) and the changes in measured head $\Delta H\left(t_{j}\right)$. (a) silt loam, (b) sandy loam, and (c) sand. Note: The limits for $K_{s}$ (or x-axis) are different for the three soils.

The most optimal set of parameters (with the highest NSE values) determined using Application 3 are reported in Table 3. Using the analysis procedure introduced by Ahmed et al. [2], the backward-fitted optimal parameters of $K_{s}$ and $\Psi$ using $\Delta H_{j}$ are $3.88 \times 10^{-4} \mathrm{~cm} / \mathrm{s}$ and $-37 \mathrm{~cm}$ for silt loam with NSE of $0.914 ; 2.80 \times 10^{-3} \mathrm{~cm} / \mathrm{s}$ and $-38 \mathrm{~cm}$ for sandy loam with NSE of $0.872 ;$ and $2.7 \times 10^{-2} \mathrm{~cm} / \mathrm{s}$ and $-8 \mathrm{~cm}$ for sand with NSE of 0.940 .

\subsection{Effects of Applying Varying Moisture Deficit $\Delta \theta$ on the Back-Fitted $\mathrm{K}_{s}$ and $\Psi$}

Results from Figure 3 show that the drawdown curve predicted using the MPDI theory is different under varying soil moisture deficit $\Delta \theta$ when $\Psi$ is changed with $\theta_{i n}$. To examine the sensitivity of the MPDI to varying $\Delta \theta$, the soil properties $K_{s}$ and $\Psi$ were back-fitted using the measured drawdown 
data for silt loam, sandy loam, and sand using different $\Delta \theta$ values including the maximum $\Delta \theta_{\max }$ and a very low $\Delta \theta$ of 0.05 and the results are summarized in Table 4 . Figure 5 shows that the simulated drawdown curves with the back-fitted $K_{s}$ and $\Psi$ using the maximum and a small $\Delta \theta$ match well with the observed drawdown data for three types of soil. The back-fitted $K_{S}$ and $\Psi$ determined using different assumed $\Delta \theta$ values are basically the same as the back-fitted $K_{s}$ and $\Psi$ using measured $\Delta \theta$ if one considers their variations determined in the laboratory or the field. This means that the back-fitted $K_{s}$ and $\Psi$ using all the drawdown data are not sensitive to $\Delta \theta$, which is the same conclusion obtained by Regalado et al [45] using the Philip-Dunne permeameter; they only measured two infiltration times when the permeameter was half full and empty. This does not mean that the Modified Philip-Dunne drawdown curves are not sensitive to the initial moisture contents, as indicated by Figure 3.

Table 4. Values of the back-fitted saturated hydraulic conductivity $K_{s}$ and the Green-Ampt suction head $\Psi$ at the wetting front for silt loam, sandy loam, and sand using different moisture deficits $\Delta \theta$.

\begin{tabular}{|c|c|c|c|c|c|}
\hline Soil Type & $\Delta \theta$ & $\begin{array}{c}K_{s} \\
(\mathrm{~cm} / \mathrm{s})\end{array}$ & $\begin{array}{c}\Psi \\
(\mathrm{cm})\end{array}$ & $\begin{array}{c}H\left(t_{1}\right) \\
(\mathrm{cm})\end{array}$ & NSE \\
\hline \multirow[t]{6}{*}{ Silt loam } & 0.211 (measured) & $3.96 \times 10^{-4}$ & -37 & 27.4 & 0.961 \\
\hline & 0.217 (maximum) & $3.82 \times 10^{-4}$ & -37 & $27.3^{a}$ & 0.961 \\
\hline & 0.050 (assumed) & $4.94 \times 10^{-4}$ & -28 & 30.2 & 0.933 \\
\hline & $\Delta \theta_{\max } / 4$ (assumed) & $4.91 \times 10^{-4}$ & -28 & 30.1 & 0.934 \\
\hline & $\Delta \theta_{\max } / 2$ (assumed) & $4.06 \times 10^{-4}$ & -35 & 29.2 & 0.966 \\
\hline & $3 \Delta \theta_{\max } / 4$ (assumed) & $3.95 \times 10^{-4}$ & -36 & 28.2 & 0.965 \\
\hline \multirow[t]{6}{*}{ Sandy loam } & 0.043 (measured) & $2.59 \times 10^{-3}$ & -44 & 50.3 & 0.968 \\
\hline & 0.222 (maximum) & $1.79 \times 10^{-3}$ & -70 & $47.2^{\mathrm{a}}$ & 0.965 \\
\hline & 0.050 (assumed) & $2.54 \times 10^{-3}$ & -45 & 50.2 & 0.969 \\
\hline & $\Delta \theta_{\max } / 4$ assumed) & $2.51 \times 10^{-3}$ & -46 & 50.1 & 0.964 \\
\hline & $\Delta \theta_{\max } / 2$ (assumed) & $2.21 \times 10^{-3}$ & -53 & 49.1 & 0.965 \\
\hline & $3 \Delta \theta_{\max } / 4$ (assumed) & $2.08 \times 10^{-3}$ & -57 & 48.2 & 0.964 \\
\hline \multirow[t]{6}{*}{ Sand } & 0.279 (measured) & $2.64 \times 10^{-2}$ & -9 & 28.8 & 0.986 \\
\hline & 0.355 (maximum) & $2.58 \times 10^{-2}$ & -9 & $27.5^{\mathrm{a}}$ & 0.986 \\
\hline & 0.050 (assumed) & $3.59 \times 10^{-2}$ & -5 & 32.7 & 0.977 \\
\hline & $\Delta \theta_{\max } / 4$ (assumed) & $3.40 \times 10^{-2}$ & -5 & 32.0 & 0.961 \\
\hline & $\Delta \theta_{\max } / 2$ (assumed) & $2.88 \times 10^{-2}$ & -8 & 30.5 & 0.986 \\
\hline & $3 \Delta \theta_{\max } / 4$ (assumed) & $2.78 \times 10^{-2}$ & -8 & 29.0 & 0.986 \\
\hline
\end{tabular}

Note: ${ }^{a}$ Minimum $H\left(t_{1}\right)$ at $\Delta \theta_{\max }$ that is used in Figure 5.

Therefore, the user of the MPDI may assume/estimate $\Delta \theta$ based on the field condition (wet or dry) to determine $K_{S}$ and $\Psi$ with a good accuracy if the user did not measure $\theta_{\text {in }}$ and/or $\theta_{S}$ since the moisture content $\theta$ values at the field capacity (for the lowest $\theta_{\text {in }}$ ) and saturated condition are available for many reference books. For example, $\Delta \theta$ can be set at $0.05, \Delta \theta_{\max } / 4, \Delta \theta_{\max } / 2,3 \Delta \theta_{\max } / 4$, and $\Delta \theta_{\max }$ depending on the observed wet to dry soil condition (Table 4). It is important to note that the same measured drawdown data of each type of soil were used to back-fit $K_{S}$ and $\Psi$ reported in Table 4 under different assumed $\Delta \theta$ values.

\section{Conclusions}

We have developed a forward model that was used to further our understanding of the fundamentals of the MPDI theory and identify some of its advantages and limitations. The forward model can be used to simulate synthetic drawdown curves that describe the changes in the water height $H\left(t_{j}\right)$ with time $t_{j}$ when the values of $K_{s}$ and $\Psi$ are known. These simulation results can be used to design the MPDI surveys under different types of field conditions. The forward model can also be used later to determine $K_{s}$ and $\Psi$ values by fitting the synthetic drawdown data against field-measured drawdown data. In this study, the model was used in this curve fitting mode to evaluate the quality of fit of 30,000 sets of randomly generated values of $K_{S}$ and $\Psi$ against the field-measured drawdown 
datasets compiled for three types of soil. Results show that the model is highly nonlinear and therefore it does not yield a unique best fit. There are multiple sets of parameters that can be used to fit the field-measured drawdown data equally well. The quality of the fit is quantified using an NSE threshold value. Our results show that for the good fits (which are delineated by NSE $\geq$ the threshold value), the predicted values of $K_{s}$ are within the expected order of magnitude value for the tested soil. However, the value of $\Psi$ can vary considerably even for good fits, especially for soils with low $K_{s}$. Based on these results, we conclude that the MPDI is a useful method to estimate $K_{s}$ but not a robust method to estimate $\Psi$. This finding is similar to the results from Gómez et al. [24] who also recommended to use alternate approaches to estimate the Green-Ampt suction head $\Psi$ at the wetting front rather than using the Philip [18] method. In addition, we found that the model fitted $K_{s}$ and $\Psi$ values are not sensitive to the assumed value of the moisture deficit $\Delta \theta$, therefore, the user of the MPDI can estimate $\Delta \theta$ based on qualitative field observations (i.e., wet or dry soil). For example, $\Delta \theta$ can be set at 0.05 for wet soils, and $\Delta \theta_{\max } / 4, \Delta \theta_{\max } / 2,3 \Delta \theta_{\max } / 4$, or $\Delta \theta_{\max }$ for different levels of partially dry to fully dry soils, respectively. Further studies are needed to simplify the current MPDI theory to fit only the $K_{s}$ values when $\Delta \theta$ and $\Psi$ values are known, or to improve the experimental procedures that can yield more sensitive datasets that can help uniquely identify $K_{s}$ and $\Psi$ values.

Author Contributions: The authors collaborated for the completion of this work. Z.A. and X.F. jointly conceived the idea and developed the first draft of this manuscript. Z.A. collected the field data for sand and silt loam using the MPDI and analyzed the data. T.P.C. provided useful ideas to improve the work and reviewed and revised the paper.

Funding: This research received no external funding.

Acknowledgments: Zuhier Alakayleh wishes to express his gratitude to Mutah University in Jordan for financial support toward his graduate study at Auburn University. Thank Farzana Ahmed for sharing the MPDI data for sandy loam.

Conflicts of Interest: The authors declare no conflict of interest.

\section{References}

1. Kanwar, R.S.; Rizvi, H.; Ahmed, M.; Horton, R.; Marley, S.J. Measurement of field-saturated hydraulic conductivity by using Guelph and velocity permeameters. Trans. ASAE 1990, 32, 1885-1890. [CrossRef]

2. Ahmed, F.; Nestingen, R.; Nieber, J.; Gulliver, J.; Hozalski, R. A Modified Philip-Dunne Infiltrometer for Measuring the Field-Saturated Hydraulic Conductivity of Surface Soil. Vadose Zone J. 2014, 13. [CrossRef]

3. Mohanty, B.; Kanwar, R.S.; Everts, C. Comparison of saturated hydraulic conductivity measurement methods for a glacial-till soil. Soil Sci. Soc. Am. J. 1994, 58, 672-677. [CrossRef]

4. Alagna, V.; Bagarello, V.; Di Prima, S.; Iovino, M. Determining hydraulic properties of a loam soil by alternative infiltrometer techniques. Hydrol. Process. 2016, 30, 263-275. [CrossRef]

5. Reynolds, W.; Bowman, B.; Brunke, R.; Drury, C.; Tan, C. Comparison of tension infiltrometer, pressure infiltrometer, and soil core estimates of saturated hydraulic conductivity. Soil Sci. Soc. Am. J. 2000, 64, 478-484. [CrossRef]

6. Alakayleh, Z.; Clement, T.P.; Fang, X. Understanding the Changes in Hydraulic Conductivity Values of Coarse-and Fine-Grained Porous Media Mixtures. Water 2018, 10, 313. [CrossRef]

7. Sällfors, G.; Öberg-Högsta, A.-L. Determination of hydraulic conductivity of sand-bentonite mixtures for engineering purposes. Geotech. Geol. Eng. 2002, 20, 65-80. [CrossRef]

8. Komine, $\mathrm{H}$. Theoretical equations on hydraulic conductivities of bentonite-based buffer and backfill for underground disposal of radioactive wastes. J. Geotech. Geoenviron. Eng. 2008, 134, 497-508. [CrossRef]

9. Sivapullaiah, P.; Sridharan, A.; Stalin, V. Hydraulic conductivity of bentonite-sand mixtures. Can. Geotech. J. 2000, 37, 406-413. [CrossRef]

10. Francisca, F.M.; Glatstein, D.A. Long term hydraulic conductivity of compacted soils permeated with landfill leachate. Appl. Clay Sci. 2010, 49, 187-193. [CrossRef]

11. Abeele, W. The influence of bentonite on the permeability of sandy silts. Nucl. Chem. Waste Manag. 1986, 6, 81-88. [CrossRef] 
12. ASTM-D5084-16a. Standard Test Methods for Measurement of Hydraulic Conductivity of Saturated Porous Materials Using a Flexible Wall Permeameter; American Society for Testing and Materials: Philadelphia, PA, USA, 2016.

13. Lee, D.; Elrick, D.; Reynolds, W.; Clothier, B. A comparison of three field methods for measuring saturated hydraulic conductivity. Can. J. Soil Sci. 1985, 65, 563-573. [CrossRef]

14. Wessolek, G.; Plagge, R.; Leij, F.; Van Genuchten, M.T. Analysing problems in describing field and laboratory measured soil hydraulic properties. Geoderma 1994, 64, 93-110. [CrossRef]

15. Mallants, D.; Jacques, D.; Tseng, P.-H.; van Genuchten, M.T.; Feyen, J. Comparison of three hydraulic property measurement methods. J. Hydrol. 1997, 199, 295-318. [CrossRef]

16. Reynolds, W.D.; Elrick, D.E. A Method for Simultaneous In Situ Measurement in the Vadose Zone of Field-Saturated Hydraulic Conductivity, Sorptivity and the Conductivity-Pressure Head Relationship. Groundw. Monit. Remediat. 1986, 6, 84-95. [CrossRef]

17. Bagarello, V.; Iovino, M.; Elrick, D. A simplified falling-head technique for rapid determination of field-saturated hydraulic conductivity. Soil Sci. Soc. Am. J. 2004, 68, 66-73. [CrossRef]

18. Philip, J. Approximate analysis of falling-head lined borehole permeameter. Water Resour. Res. 1993, 29, 3763-3768. [CrossRef]

19. ASTM-D8152-18. Standard Practice for Measuring Field Infiltration Rate and Calculating Field Hydraulic Conductivity Using the Modified Philip Dunne Infiltrometer Test; American Society for Testing and Materials: Philadelphia, PA, USA, 2018.

20. Merva, G. The velocity permeameter technique for rapid determination of hydraulic conductivity in situ. In Proceedings of the 3rd Workshop on Land Drainage, Columbus, OH, USA, 7-11 December 1987.

21. Perroux, K.; White, I. Designs for Disc Permeameters. Soil Sci. Soc. Am. J. 1988, 52, 1205-1215. [CrossRef]

22. Bouwer, H. Measuring Horizontal and Vertical Hydraulic Conductivity of Soil With the Double-Tube Method 1. Soil Sci. Soc. Am. J. 1964, 28, 19-23. [CrossRef]

23. Reynolds, W.; Elrick, D. Ponded infiltration from a single ring: I. Analysis of steady flow. Soil Sci. Soc. Am. J. 1990, 54, 1233-1241. [CrossRef]

24. Gómez, J.; Giráldez, J.; Fereres, E. Analysis of infiltration and runoff in an olive orchard under no-till. Soil Sci. Soc. Am. J. 2001, 65, 291-299. [CrossRef]

25. Connolly, R.D.; Silburn, D.M.; Ciesiolka, C.A.A.; Foley, J.L. Modelling hydrology of agricultural catchments using parameters derived from rainfall simulator data. Soil Tillage Res. 1991, 20, 33-44. [CrossRef]

26. Muñoz-Carpena, R.; Regalado, C.M.; Álvarez-Benedi, J.; Bartoli, F. Field evaluation of the new Philip-Dunne permeameter for measuring saturated hydraulic conductivity. Soil Sci. 2002, 167, 9-24. [CrossRef]

27. Nestingen, R.; Asleson, B.C.; Gulliver, J.S.; Hozalski, R.M.; Nieber, J.L. Laboratory Comparison of Field Infiltrometers. J. Sustain. Water Built Environ. 2018, 4, 04018005. [CrossRef]

28. Zhang, R. Determination of soil sorptivity and hydraulic conductivity from the disk infiltrometer. Soil Sci. Soc. Am. J. 1997, 61, 1024-1030. [CrossRef]

29. Weiss, P.T.; Gulliver, J.S. Effective saturated hydraulic conductivity of an infiltration-based stormwater control measure. J. Sustain. Water Built Environ. 2015, 1, 04015005. [CrossRef]

30. García-Serrana, M.; Gulliver, J.S.; Nieber, J.L. Infiltration capacity of roadside filter strips with non-uniform overland flow. J. Hydrol. 2017, 545, 451-462. [CrossRef]

31. Kristvik, E.; Kleiven, G.H.; Lohne, J.; Muthanna, T.M. Assessing the robustness of raingardens under climate change using SDSM and temporal downscaling. Water Sci. Technol. 2018, 77, 1640-1650. [CrossRef] [PubMed]

32. Taguchi, V.J.; Carey, E.S.; Hunt III, W.F. Field Monitoring of Downspout Disconnections to Reduce Runoff Volume and Improve Water Quality along the North Carolina Coast. J. Sustain. Water Built Environ. 2018, 5, 04018018. [CrossRef]

33. Nestingen, R.S. The Comparison of Infiltration Devices and Modification of the Philip-Dunne Permeameter for the Assessment of Rain Gardens. Master's Thesis, University of Minnesota, Minneapolis, MN, USA, 2007.

34. ASTM-D2216-10. Standard Test Methods for Laboratory Determination of Water (Moisture) Content of Soil and Rock by Mass; American Society for Testing and Materials: Philadelphia, PA, USA, 2010.

35. ASTM-F1815-11. Standard Test Methods for Saturated Hydraulic Conductivity, Water Retention, Porosity, and Bulk Density of Athletic Field Rootzones; American Society for Testing and Materials: Philadelphia, PA, USA, 2011.

36. Clapp, R.B.; Hornberger, G.M. Empirical equations for some soil hydraulic properties. Water Resour. Res. 1978, 14, 601-604. [CrossRef] 
37. Nash, J.E.; Sutcliffe, J.V. River flow forecasting through conceptual models part I-A discussion of principles. J. Hydrol. 1970, 10, 282-290. [CrossRef]

38. Rawls, W.J.; Brakensiek, D.L.; Saxtonn, K. Estimation of soil water properties. Trans. ASAE 1982, 25, 1316-1320. [CrossRef]

39. Brooks, R.H.; Corey, A.T. Properties of porous media affecting fluid flow. J. Irrig. Drain. Div. 1966, 92, 61-90.

40. Philip, J. The theory of infiltration: 5. The influence of the initial moisture content. Soil Sci. 1957, 84, 329-340. [CrossRef]

41. Gray, D.M.; Norum, D. The effect of soil moisture on infiltration as related to runoff and recharge. In Proceedings of the Hydrology Symposium No. 6 Soil Moisture, Saskatoon, SK, Canada, 15-16 November 1967.

42. Ruggenthaler, R.; Meißl, G.; Geitner, C.; Leitinger, G.; Endstrasser, N.; Schöberl, F. Investigating the impact of initial soil moisture conditions on total infiltration by using an adapted double-ring infiltrometer. Hydrol. Sci. J. 2016, 61, 1263-1279. [CrossRef]

43. Ahmed, F. Characterizing the Performance of a New Iniltrometer and Hydraulic Properties of Roadside Swales. Ph.D. Thesis, University of Minnesota, Minneapolis, MN, USA, 2014.

44. Durner, W.; Lipsius, K. Determining Soil Hydraulic Properties. Encycl. Hydrol. Sci. 2005, 1021-1144. [CrossRef]

45. Regalado, C.M.; Ritter, A.; Alvarez-Benedi, J.; Munoz-Carpena, R. Simplified method to estimate the Green-Ampt wetting front suction and soil sorptivity with the Philip-Dunne falling-head permeameter. Vadose Zone J. 2005, 4, 291-299. [CrossRef]

(C) 2019 by the authors. Licensee MDPI, Basel, Switzerland. This article is an open access article distributed under the terms and conditions of the Creative Commons Attribution (CC BY) license (http://creativecommons.org/licenses/by/4.0/). 